\title{
Processos de Auto-Regulação no Curso de Vida: Controle Primário e Controle Secundário
}

\section{Self-Regulation Processes in the life-Course: Primary and Secondary Control}

\author{
Hilma Tereza Tôrres Khoury ${ }^{*} a$ \& Isolda de Araújo Günther ${ }^{b}$ \\ ${ }^{a}$ Universidade Federal do Pará \\ ${ }^{b}$ Universidade Nacional de Brasília
}

\begin{abstract}
Resumo
Este artigo discute conceitos relevantes à perspectiva do curso de vida, porém pouco difundidos no Brasil: controle primário e controle secundário. O primeiro se refere aos esforços que o indivíduo empreende para adaptar o ambiente às suas necessidades; o segundo, para se adaptar ao ambiente. Apresenta-se a formulação original dos conceitos como modelo de dois processos de controle, em oposição a modelos de processo único, como o do desamparo aprendido. Em seguida, discute-se revisão conceitual que trouxe modificação e ampliação para estes construtos, concebendo-os em um modelo bidimensional que articula controle primário e secundário com os conceitos de seleção e compensação. Nesse processo, apresentam-se contribuições no intuito de estimular a reflexão e expandir a discussão teórico-conceitual que envolve estes construtos.

Palavras-chave: Controle pessoal; percepção de controle; curso de vida; auto-regulação; controle primário e secundário.

Abstract

This article discusses relevant concepts of life course perspective which are not very much diffused in Brazil: primary and secondary control. The former refers to efforts to change the environment so that it fits individual's needs. The latter involves efforts to fit in with the environment. The original definitions are presented as a twoprocess model of control in contrast to one-process models such as learned helplessness. Furthermore, it discusses a conceptual revision, which modified and expanded these constructs as a bi-dimensional model that relates primary and secondary control to the concepts of selection and compensation. In process of arguing about those, suggestions are presented for thinking and expanding the theoretical and conceptual discussion of these constructs.

Keywords: Personal control; sense of control; life-course; self-regulation; primary and secondary control.
\end{abstract}

No decorrer do curso de vida os indivíduos utilizam diversos processos para regular o próprio desenvolvimento. Esses processos se constituem em mecanismos que, por um lado, servem de auxílio para enfrentar os desafios e alcançar os fins desejados. Por outro lado, favorecem a adaptação às inevitáveis perdas que ocorrem ao longo da vida. Tais mecanismos ou estratégias têm sido abordados na literatura por meio de termos como auto-eficácia, competência, controle pessoal, senso de controle, enfrentamento, lócus de controle e resiliência, dentre outros. Neste quadro de referência dois conceitos-chave chamam a atenção: controle primário e controle secundário.

\footnotetext{
* Endereço para correspondência: Universidade Federal do Pará, Instituto de Filosofia e Ciências Humanas, Faculdade de Psicologia, Campus Universitário do Guamá, Rua Augusto Corrêa, 01, Belém, PA, Brasil, CEP 66075-110. E-mail: hilmatk@yahoo.com.br

Este artigo é fruto da revisão de literatura efetuada para pesquisa que resultou em Tese de Doutorado da primeira autora, orientada pela segunda autora na Universidade de Brasília, intitulada "Controle primário e controle secundário: Relação com indicadores de envelhecimento bem-sucedido".
}

Propõe-se, neste artigo, apresentar os conceitos de controle primário e controle secundário tal como originalmente elaborados por Rothbaum, Weiss e Snyder (1982), discutir a revisão conceitual efetuada por Heckhausen e Schulz (1995) e, nesse processo, contribuir para ampliar a discussão teórica e conceitual que envolve estes construtos.

Historicamente, os termos controle primário e controle secundário apareceram na literatura no domínio da psicologia social, em Rothbaum et al. (1982) e se referem aos recursos pessoais disponíveis e ao uso eficaz de tais recursos para regular o próprio desenvolvimento, isto é, como formas de controle pessoal.

Posteriormente, tais conceitos foram empregados no quadro teórico da psicologia do desenvolvimento, particularmente pelos estudiosos do curso de vida e do chamado desenvolvimento bem-sucedido (Heckhausen, 2001; Heckhausen \& Schulz, 1993, 1995; Schulz \& Heckhausen, 1996).

O fato de utilizarem as mesmas palavras, controle primário e controle secundário, pode sugerir que os grupos de Rothbaum e de Heckhausen comungam dos mesmos 
conceitos. Contudo, estes autores diferem quanto às definições; à compreensão de como esses processos se relacionam ao desenvolvimento humano e à maneira como engendram resultados adaptativos.

Rothbaum et al. (1982) definiram controle primário e secundário em termos da meta do indivíduo, mudar o ambiente, no primeiro caso, ou a ele adaptar-se, no segundo. Para Heckhausen e Schulz (1995), a distinção entre controle primário e secundário se dá por meio do alvo ao qual o indivíduo se dirige: mundo externo, no primeiro caso; self, no segundo. A despeito da similaridade de significados entre as palavras meta e alvo, assim como da aparente correspondência lógica entre as expressões mudar o ambiente e mundo externo, por um lado e adaptar-se ao ambiente e self, por outro, o leitor verá mais adiante que os dois grupos de autores divergem conceitualmente sobre esta questão.

No que diz respeito à relação dos controles primário e secundário com o desenvolvimento humano, Rothbaum et al. (1982) conceberam a adaptabilidade como equilíbrio entre os dois processos de controle. Por sua vez, Heckhausen e Schulz (1995) atribuíram o desenvolvimento bem-sucedido à manutenção do controle primário ao longo do curso de vida.

\section{Controle Primário e Secundário: Formulação Original}

Rothbaum et al. (1982) elaboraram o modelo de dois processos - controle primário e controle secundário - como alternativa aos modelos de processo único, tal como o do desamparo aprendido (Seligman, 1977) e o do lócus de controle (Lefcourt, 1976; Rotter, 1966). Na teoria do desamparo aprendido (Seligman, 1977), comportamentos de passividade; afastamento e submissão, exibidos depois de repetidas tentativas fracassadas, foram interpretados como manifestações de abandono da motivação para controle. Na teoria do lócus de controle (Lefcourt, 1976; Rotter, 1966), o lócus de controle externo, ou seja, a tendência a atribuir resultados à forças fora de si próprio, tais como sorte ou destino, foi vinculado a percepção de falta de controle. Contrariando os modelos de processo único Rothbaum et al. propuseram que tais comportamentos e atribuições podem estar refletindo outro tipo de controle. A partir daí distinguiram entre controle primário e controle secundário.

O controle primário foi definido por Rothbaum et al. (1982) como um processo que envolve "esforços para modificar o ambiente, de forma a adaptá-lo às necessidades do indivíduo" (p. 8). O controle secundário é um processo que envolve "esforços para adaptar-se ao ambiente e fluir com a corrente" (p. 8).

Para estes autores, os teóricos dos modelos de processo único, particularmente o do desamparo aprendido (Seligman, 1977) enfatizaram, por um lado, a capacidade para mudar o ambiente e, por outro, a ausência de esforços para mudar o ambiente, bem como a ausência da motivação para controle. Desta forma, teriam equiparado sua noção de controle ao que Rothbaum et al. (1982) denominaram de con- trole primário, ignorando um segundo processo, aquele que os autores definiram como controle secundário. Rothbaum et al. argumentaram que "a motivação para sentir-se "no controle' pode ser expressa não apenas em comportamentos que estão claramente controlando, mas também sutilmente, em comportamentos que não estão" (p. 7).

Assim como os teóricos dos modelos de processo único, Rothbaum et al. (1982) admitiram que experiências de fracasso conduzem a comportamentos de passividade, afastamento e submissão. Entretanto, sustentaram que nem sempre tais comportamentos estariam refletindo abandono da motivação para controle, pois esses comportamentos seriam "freqüentemente motivados" (p. 27) e, em muitos casos, "podem ser iniciados e mantidos em um esforço para preservar percepções de controle" (p. 7).

Tal motivação e esforço para obter controle secundário seriam evidenciados, conforme Rothbaum et al. (1982), em várias formas de "comportamento persistente caracterizado por um generalizado esforço no sentido de adaptar-se efetivamente ao ambiente" (p. 27). A persistência de alguns desses comportamentos introvertidos ou subordinados, argumentam, seria evidente, por exemplo, nos pensamentos e ações perseverantes de obsessivo-compulsivos, o que sugere que "o comportamento satisfaz algum propósito subjacente e que não reflete meramente um 'déficit' na motivação" (p. 7).

Em defesa do modelo de dois processos, Rothbaum et al. (1982) afirmaram que "o controle é tão valorizado que a procura por ele raramente é abandonada; ao invés disso, os indivíduos provavelmente mudam de um para outro método de buscar controle" (p. 7). Os autores sustentaram que o controle primário - "esforço para modificar coisas que oferecem resistência" - tende a produzir satisfação por sucessos, mas também desapontamento por falhas. Já o controle secundário - "esforço para ajustar-se às resistências" - tende a ser experimentado como mais seguro e a conduzir a menos extremos de altos e baixos (p. 8). Por esta razão, sugeriram que a busca do controle secundário pode representar "um esforço para manter a crença na eventual efetividade do controle primário" (p. 9). Assim, a tendência a se modificar para adaptar-se mais efetivamente ao ambiente protegeria a tendência a modificar o ambiente para adaptá-lo às próprias necessidades.

Entretanto, Rothbaum et al. (1982) chamaram a atenção para o fato de que nenhum dos dois processos de controle existiria em forma pura. Ambos estariam freqüentemente inter-relacionados, "como quando as pessoas negociam e entram em um acordo" (p. 8). Ressaltaram, também, que há oscilação freqüente entre os dois processos de controle "como quando as pessoas alternam entre fases de luta e fuga ao lidar com uma incapacidade física" (p. 8). Concluíram, assim, que "as diferenças entre controle primário e controle secundário deveriam ser pensadas como diferenças em ênfase" (p. 8).

Apesar de reconhecerem inter-relação e oscilação freqüentes entre os dois processos de controle, e de afirmarem que a diferença entre eles é de ênfase, Rothbaum et al. (1982) assumiram outra diferença entre esses dois proces- 
sos de controle, relacionada à sequiência temporal, pois, para eles, o controle secundário ocorreria após tentativas de controle primário terem fracassado.

Todas essas colocações referentes à inter-relação e oscilação entre os dois processos de controle parecem dizer respeito à dinâmica desses processos no dia-a-dia dos indivíduos. Prosseguindo neste trabalho de diferenciação, Rothbaum et al. (1982) estabeleceram a diferença básica entre controle primário e secundário. Afirmaram que "a diferença-chave entre controle primário e secundário é que, no primeiro caso, a meta é mudar o ambiente enquanto que no último caso, a meta é adaptar-se ao ambiente" (p. 11). Percebe-se, assim, que a principal distinção se encontra no objetivo ou finalidade do indivíduo, mudar o ambiente ou adaptar-se a ele.

Para ilustrar o modelo de dois processos em contraposição aos modelos de processo único e marcar a diferença-chave entre os dois construtos, controle primário e controle secundário, Rothbaum et al. (1982) selecionaram quatro formas de controle - preditivo, ilusório, vicário e interpretativo - e descreveram como os processos de controle primário e secundário se manifestam em cada uma delas, por meio de uma combinação de comportamentos, atribuições e eventos precipitantes. No controle preditivo, o processo primário seria caracterizado por esforços para "prever eventos de forma a ter êxito" (Rothbaum et al. p. 12). Isto incluiria "comportamento ativo" e "atribuições ao próprio esforço e capacidade, especialmente em tarefas com grau de dificuldade moderado" (p. 12). O processo secundário seria assinalado por esforços para "prever eventos de forma a evitar desapontamentos" (p. 12) abrangendo "atribuições à capacidade seriamente limitada" combinadas com "comportamento passivo e de afastamento, especialmente em tarefas com grau de dificuldade moderado" ou com "comportamento ativo e persistente em situações extremamente fáceis ou difíceis" (p. 12). No controle secundário de tipo preditivo, a previsibilidade "permite ao indivíduo ajustar-se ao evento incontrolável, tornando-o desta forma, em um sentido secundário, controlável" (p. 15). Este tipo de controle seria mais comum em pessoas com baixa auto-estima ou que repetidamente experimen-taram fracassos.

No controle ilusório, o processo secundário apareceria em uma associação do indivíduo com a sorte, "de forma a compartilhar do poder desta grande força" (Rothbaum et al., 1982, p. 11). "A sorte é vista como uma propriedade do indivíduo" (p. 11); as pessoas dizem que têm sorte ou que nasceram com sorte, vendo-a "como um aliado em quem podem confiar" (p. 11). São prováveis de ocorrer "comportamento ativo em situações que dependem do acaso" (p. 12) como, por exemplo, comportamentos supersticiosos e rituais, "mas comportamento passivo e de afastamento em situações que dependem das habilidades do sujeito" (p. 12). Rothbaum et al. afirmaram que "o controle secundário está estreitamente relacionado ao lócus de controle externo" (p. 20). Pessoas com lócus de controle externo perceberiam o controle primário como improvável ou impossível e sentir-se-iam motivadas a ver a sorte como algo estável e controlável (p. ex. "Eu sou uma pessoa de sorte"), ganhando com isso controle secundário. O processo primário se evidenciaria em uma percepção distorcida de situações determinadas pelo acaso como situações que dependem das habilidades do indivíduo, o que conduziria a comportamento ativo (p. ex. supersticiosos) tais como escolha e esforço em situações cujos resultados os sujeitos não podem influenciar.

Prosseguindo em sua exemplificação do modelo de dois processos, Rothbaum et al. (1982) abordaram o controle vicário e o controle interpretativo. $\mathrm{O}$ controle vicário se assemelha ao ilusório, porém, o processo secundário se caracterizaria por uma associação do indivíduo com outros poderosos "a fim de compartilhar de suas vitórias e seus talentos - em suma, de seu controle" (p. 20). Ao lado de atribuições de resultados aos outros poderosos ocorrem comportamentos não-instrumentais e submissos. A submissão deliberada aos outros poderosos e a satisfação dela decorrente assinalaria o controle secundário. O processo primário se caracterizaria por "esforços para manipular outros poderosos ou imitar seu poder ou habilidade" (p. 12), o que incluiria comportamento instrumental submisso ou manipulador, assim como atribuições ao próprio esforço e capacidade. São exemplos de controle vicário a associação que crianças e adolescentes fazem de si próprias com heróis ou ídolos, dos quais derivam senso de poder; o fenômeno religioso, quando o crente acredita ganhar poder através de sua devoção a Deus, santos ou outros entes espirituais; ou ainda a pertença a grupos que massificam, conduzindo à despersonalização.

No controle interpretativo, o processo primário seria indicado por esforços para "compreender problemas de forma a ser capaz de resolvê-los ou, por outro lado, dominá-los" (Rothbaum et al., 1982, p. 12), incluindo "comportamento ativo" e "atribuições ao próprio esforço e capacidade" (p. 12). O processo secundário se faria notar em esforços para "compreender problemas, de forma a derivar significado deles e aceitá-los" (p. 12), envolvendo "comportamento passivo; de afastamento e submisso", assim como "atribuições à capacidade seriamente limitada, à sorte e a outros poderosos" (p. 12). Nesse sentido, dizem os autores, o controle interpretativo estaria relacionado às outras três formas de controle. Este tipo de controle seria mais freqüente em situações onde há pouco controle primário, bem como após experiências de falha ou perda. A descoberta de significados faria as pessoas se sentirem mais efetivas.

Rothbaum et al. (1982) admitiram que sua noção de controle interpretativo baseia-se parcialmente na pesquisa acerca de estratégias de enfrentamento, onde o estresse diminui quando as pessoas interpretam positivamente uma situação dolorosa. Os autores afiançaram que "a diminuição do estresse reflete a obtenção bem-sucedida de um tipo de controle secundário - a descoberta de significados - e, por meio disso, a capacidade para aceitar eventos potencialmente aversivos" (p. 26).

Finalmente, Rothbaum et al. (1982, p. 29) relacionaram adaptabilidade com controle primário e secundário. Mar- 
cando a diferença entre seu modelo de dois processos e os modelos de processo único, particularmente o de Seligman (1977), afirmaram que, diferentemente deste, onde adaptabilidade é definida "em termos do nível absoluto de controle (primário)", o modelo de dois processos define adaptabilidade "em termos dos níveis relativos de controle primário e controle secundário". Segundo os próprios autores, "a mudança de um enfoque do ótimo grau de controle para um enfoque do ótimo equilíbrio entre diferentes processos de controle é uma das mais significativas implicações do modelo de dois processos" (p. 29).

Contudo, argumentaram os autores, é muito difícil determinar qual equilíbrio seria mais adaptativo, uma vez que isso envolveria valores, os quais, por sua vez, são afetados pelos contextos culturais nos quais as pessoas se encontram, além de depender também da perspectiva temporal e das circunstâncias. Por essa razão, propuseram que adaptabilidade ou "bom ajustamento" seja conceitualmente definido como "um conhecimento de como e quando aplicar os dois processos de controle e como integrá-los" (Rothbaum et al., 1982, p. 30). Citaram como exemplo da importância dessa integração o caso de vítimas de paralisia que, por um lado, empreendem esforços para descobrir significados e aceitar aspectos dessa situação irreversível e, por outro, esforçam-se para dominar a habilidade de solucionar novos problemas em áreas onde o controle primário ainda é possível.

Em publicações posteriores, os autores em conjunto com colaboradores (Band \& Weisz, 1988; Thurber \& Weisz, 1997; Weisz, McCabe, \& Dennig, 1994; Weisz, Rothbaum, \& Blackburn, 1984) analisaram dados empíricos, reafirmaram o modelo de dois processos e apresentaram refinamento para os conceitos de controle primário e secundário. Ressalta-se a distinção destes construtos em termos de estratégia geral, alvo e intenção (Weisz et al., 1984). A estratégia geral no controle primário é influenciar realidades existentes, o alvo da influência são outras pessoas, objetos, comportamentos e circunstâncias ambientais e a intenção é aumentar recompensas ou reduzir custos por meio da adaptação destas realidades a si, visando à individualidade e autonomia pessoal. No controle secundário, a estratégia geral é acomodar-se às realidades existentes, o alvo é o indivíduo - suas expectativas, desejos, metas, percepções, atitudes, interpretações, atribuições - e a intenção é aumentar recompensas ou reduzir custos por meio da adaptação de si às pessoas, objetos ou circunstâncias ambientais, visando influenciar seu impacto psicológico sobre o self.

A seguir será apresentada a revisão dos conceitos de controle primário e controle secundário empreendida por Heckhausen e Schulz (1995).

\section{A Perspectiva de Heckhausen e Schulz}

Partindo do trabalho de Rothbaum et al. (1982) e apoiados no modelo de otimização seletiva com compensação (SOC) elaborado por Baltes e Baltes (1990), Heckhausen e
Schulz (1995) formularam a teoria do controle no curso de vida e seu correspondente modelo de desenvolvimento bem-sucedido (Schulz \& Heckhausen, 1996), adotando o construto de controle como tema central para a caracterização do desenvolvimento humano da infância à velhice. Contudo, estes autores revisaram os conceitos de controle primário e secundário e propuseram uma modificação na definição originalmente concebida por Rothbaum et al.

Heckhausen e Schulz (1995) argumentaram que o sentido dado ao controle primário - ajustar o ambiente às necessidades do indivíduo - e ao controle secundário - ajustar-se ao ambiente - contido na definição elaborada por Rothbaum et al. (1982) teria duas implicações. Primeiro, interpretaram os autores, "a ação é dirigida ao exterior, para o mundo externo, no controle primário, e ao interior, em direção ao indivíduo, no controle secundário" (Heckhausen \& Schulz, 1995, p. 285). Segundo, "os processos de controle primário envolvem ação direta sobre o ambiente, enquanto que os processos de controle secundário são basicamente cognitivos" (p. 285). Desta forma, poder-se-ia pensar em definir controle primário e controle secundário "em termos de dois atributos ortogonais, cada qual com dois níveis: alvo (mundo externo x self) e processos (ação x cognição)" (p. 285).

Heckhausen e Schulz (1995) reconheceram o valor heurístico desses dois níveis para a distinção dos construtos de controle primário e secundário. No entanto, argumentaram que isto pode gerar dificuldades quando se tenta classificar comportamentos específicos ou cognições como exemplos de controle primário ou secundário. Para ilustrar esta assertiva, tomaram como exemplo a comparação social com outros em posição menos favorável, em caso de falha ou de perda, a fim de elevar a auto-estima, fato que tem sido tratado na literatura como exemplo de controle secundário. Observaram que a comparação social é "um processo cognitivo dirigido ao self' (p. 285), porém, o análogo comportamental desse processo - "procurar outros para comparação social e aumento da auto-estima" (p. 285) seria mais difícil de classificar. A comparação social, dizem, "envolve ação e cognição, seu último alvo é o self e envolve, ainda, engajamento com o mundo externo" (p. 285). Assim, propuseram distinguir entre controle primário e secundário principalmente pelo alvo (isto é, self $\mathrm{x}$ mundo externo) ao invés do processo envolvido (ação $\mathrm{x}$ cognição), "uma vez que, na prática, cognição e ação estão freqüentemente inter-relacionadas de forma tão estreita que se torna difícil separar uma da outra" (p. 285).

Aparentemente, a definição de controle primário e controle secundário proposta por estes autores não difere da acepção original. "O controle primário tem como alvo o mundo externo e esforça-se para produzir efeitos no ambiente imediato, externo ao indivíduo, enquanto que o controle secundário tem como alvo o self e esforça-se para produzir mudanças diretamente no indivíduo" (Heckhausen $\&$ Schulz, 1995, p. 285). Contudo, embora admitindo que "ambos, controle primário e controle secundário podem envolver cognição e ação" (p. 285), restringiram o contro- 
le primário à ação e o controle secundário à cognição. Isto fica claro quando complementam esta afirmação dizendo: "ainda que o controle primário seja quase sempre caracteri-zado em termos de comportamento ativo, engajado no mundo externo, enquanto que o controle secundário seja predominantemente caracterizado em termos de processos cognitivos localizados no indivíduo" (p. 285). Caso a expressão "quase sempre caracterizado" suscite qualquer dúvida, esta se dissipa logo adiante no texto quando sentenciam: "a distinção básica entre controle primário e secundário é que o controle primário envolve comportamentos dirigidos ao mundo externo, enquanto que o controle secundário envolve atividades internas ao indivíduo" (p. 286).

Em outras publicações (Heckhausen, 2001; Schulz \& Heckhausen, 1996) os autores reafirmaram o caráter comportamental do controle primário e o cognitivo do controle secundário. O controle secundário é direcionado para o mundo interno do indivíduo e "serve para otimizar os recursos motivacionais e emocionais" (Heckhausen, 2001, p. 370).

Discutindo a importância do suporte social para a saúde e o bem-estar, Krause (2001) lamenta que Schulz e Heckhausen (1996) tenham visto o controle secundário "somente em termos de cognições internas" (p. 275), desconsiderando a literatura que aponta o papel dos "outros significativos" (p. 276) no sentido de ajudar na manutenção do senso de controle.

Quando Heckhausen e Schulz (1995) propõem distinguir controle primário e secundário por meio do alvo, isto é, mundo externo/self, parecem perder de vista o propósito de Rothbaum et al. (1982) de diferenciá-los em termos da meta do indivíduo em relação ao ambiente - adaptá-lo à si ou adaptar-se a ele. Embora Rothbaum et al. entendam o controle primário como mudança do ambiente e o controle secundário como mudança do self, e a despeito da similaridade de significados entre as palavras alvo e meta, a questão central para Rothbaum et al. é a motivação do indivíduo para adaptar o ambiente a si ou adaptar-se a ele.

Além disso, ao associar o controle primário à ação e o controle secundário à cognição, Heckhausen e Schulz (1995) parecem desprezar as demonstrações de Rothbaum et al. (1982) na direção de que, tanto o esforço para mudar o ambiente, quanto o esforço para adaptar-se a ele, incluem cognição e ação. A manifestação das quatro formas de controle apontadas por Rothbaum et al. - preditivo, ilusório, vicário e interpretativo - seja como processo primário ou como processo secundário, ocorre por meio de comportamentos e atribuições, portanto, ações e cognições. Rothbaum et al. não fazem qualquer referência no sentido de uma ter peso maior que a outra em quaisquer dos dois processos de controle. Para eles, o que permite determinar o processo em evidência no sujeito - primário ou secundário - é o conjunto de comportamentos e atribuições em um dado contexto. E o fundamental nesse contexto é a motivação do indivíduo, seu objetivo ou finalidade: mudar o ambiente ou adaptar-se a ele.
A distinção que Heckhausen e Schulz (1995) fizeram do controle primário e do controle secundário por meio do alvo - mundo externo/self - aliado à ênfase na ação para o primeiro e na cognição para o segundo, modificou o sentido originalmente atribuído a estes construtos por Rothbaum et al. (1982).

Pouco depois da publicação da teoria do controle no curso de vida, um dos autores da formulação original (Thurber \& Weisz, 1997) parece ter levado em conta os argumentos de Heckhausen e Schulz (1995) acerca da dificuldade para se classificar comportamentos e cognições como exemplos de controle primário ou secundário, quando se considera simultaneamente o alvo - mundo externo/self - e o processo - ação/cognição. Thurber e Weisz (1997) distinguiram entre métodos e metas de enfrentamento: "Métodos são maneiras de agir ou pensar; metas são os fins aos quais os métodos de enfrentamento se dirigem" (p. 509). Os autores argumentaram que, de forma ampla, os métodos podem ser classificados em "comportamentos observáveis e não-observáveis" (p. 509) e afirmaram que "os conceitos de controle primário e secundário se aplicam apenas às metas de enfrentamento porque somente metas têm um objeto de controle, seja o self (controle secundário) ou as condições objetivas (controle primário)" (p. 509). Assim, Thurber e Weisz (1997) aperfeiçoaram a diferenciação original dos dois processos de controle por meio da meta, mantendo a utilização de ação/cognição em ambas. Isto fica claro no instrumento que utilizaram nesse estudo; os autores classificaram os itens a partir de uma combinação de dois níveis, método - observável/não-observável - e meta - primária/secundária. Itens rotulados como método observável/meta secundária (p. ex. "Fazer algo divertido para esquecer que está longe de casa") indicam a utilização de comportamentos quando a finalidade é obter controle secundário.

Além do conceito de controle primário e secundário, Heckhausen e Schulz (1995) analisaram também o valor funcional ou adaptativo destes dois construtos para o indivíduo. Entenderam que na concepção de Rothbaum et al. (1982) os processos de controle primário e secundário têm valor funcional similar para o organismo e advogaram em favor da primazia funcional do controle primário sobre o secundário.

Heckhausen e Schulz (1995) argumentaram que os indivíduos preferirão e se esforçarão pelo controle primário mais do que pelo controle secundário; que o esforço por agir frente aos eventos é parte do acabamento determinado pela evolução das espécies; e que o controle primário é a referência básica não apenas nos humanos, mas nos mamíferos em geral. Assim, defenderam a primazia do controle primário como uma característica universal do comportamento humano, que seria invariável através das culturas e da história.

Afirmaram os autores que, "por ser o controle primário dirigido para fora, capacita os indivíduos a moldar seu ambiente de forma a adaptá-lo às suas necessidades particulares e ao seu potencial de desenvolvimento" (Heckhausen 
Khoury, H. T. T. \& Günther, I. A. (2009). Processos de Auto-Regulação no Curso de Vida: Controle Primário e Controle Secundário.

\& Schulz, 1995, p. 286) e que, "sem o engajamento no mundo externo, o potencial de desenvolvimento do organismo não pode ser realizado" (p. 286). Por isso, o controle primário seria "preferido" e teria "maior valor adaptativo para o indivíduo" (p. 286).

Dados empíricos provenientes de estudos transculturais contestaram a primazia (Gould, 1999) ou preferência (Weisz et al., 1984) pelo controle primário como característica universal. A comparação entre culturas ocidentais e orientais revelou que nestas o controle secundário desempenha um papel mais central. Em resposta a Gould, Heckhausen e Schulz (1999) esclareceram que a defesa da primazia do controle primário não supõe invariância em diferentes culturas quanto às manifestações preferenciais de uma ou outra estratégia de controle. Refere-se ao fato de que "o esforço por controle primário desenvolveu-se na filogênese por seu valor adaptativo para a sobrevivência e a procriação" (Heckhausen \& Schulz, p. 608), assim, ontogeneticamente precede o controle secundário no sistema motivacional que regula o comportamento humano e isto é "invariável cultural e historicamente" (p. 605).

Rothbaum et al. (1982) não discutiram controle primário e secundário em termos do grau de importância funcional de cada um. Conceberam adaptabilidade em termos dos níveis relativos de controle primário e secundário ou do "equilíbrio ótimo" (p. 29) entre os diferentes processos de controle. Contudo, estes autores admitiram uma "diferença na seqüência temporal dos processos de controle" (p. 8) e afirmaram que "o controle secundário é mais provável de ocorrer após tentativas fracassadas de controle primário" (p. 8). Porém, a grande preocupação de Rothbaum et al. foi, sem dúvida, mostrar que o controle pessoal não é um processo de mão única, cuja ausência implica necessariamente em falta de controle. É um processo de mão dupla - primário e secundário. Se não é possível ao indivíduo obter controle por uma via, ele tenta consegui-lo pela outra. Assim, com fartos dados experimentais, mostraram que onde aparentemente há falta de controle, pode estar atuando outro tipo de controle, o secundário.

Apesar da crítica que fizeram a Rothbaum et al. (1982) quanto a atribuir valor funcional equivalente aos controles primário e secundário, o objetivo que Heckhausen e Schulz (1995) se propõem atingir em sua teoria do controle no curso de vida é "descrever o equilíbrio ótimo entre as estratégias de controle primário e secundário ao longo do curso de vida e a maneira pela qual este equilíbrio pode ser alcançado" (p. 290).

A posição de Heckhausen e Schulz (1995) quanto à primazia do controle primário sobre o controle secundário é assaz relevante do ponto de vista teórico para a psicologia e poderia conduzir à discussão filosófica acerca da materialidade do pensamento. Não obstante, ao propor a primazia do controle primário sobre o secundário, Heckhausen e Schulz (1995) parecem ter encontrado uma posição conciliadora entre aquela que defende adaptabilidade em termos de níveis absolutos de controle (Seligman, 1977) e aquela que defende adaptabilidade em termos de equilíbrio entre dois processos de controle - primário e secundário (Rothbaum et al., 1982).

Além da revisão conceitual e da defesa de primazia do controle primário sobre o secundário, Heckhausen e Schulz (1995) propuseram ainda a ampliação das funções do controle secundário para além da compensação em caso de falha/perda no controle primário. Antes de abordar essa proposição dos autores, porém, faz-se necessário expor, ainda que de forma extremamente resumida, sua concepção de desenvolvimento e a articulação que fazem do controle primário e secundário com a seleção e a compensação advindas do modelo SOC de Baltes e Baltes (1990).

Em sua teoria do controle no curso de vida e em seu modelo de desenvolvimento bem-sucedido, os autores (Heckhausen \& Schulz, 1993, 1995; Schulz \& Heckhausen, 1996) argumentaram que, ao longo do ciclo de vida, os indivíduos encontram desafios, oportunidades e restrições ao seu desenvolvimento. De um lado, os principais desafios incluem a necessidade de ser seletivo na escolha de trajetórias a seguir e a tendência a falhas do comportamento humano. De outro lado, as principais restrições e oportunidades são de ordem biológica e social. O indivíduo precisaria administrar os desafios ao seu desenvolvimento ao longo da vida, conforme as oportunidades disponíveis e as restrições a ele colocadas, podendo intensificar a seletividade por meio do investimento em recursos, ou recorrer a compensações quando perdas são experimentadas ou antecipadas. Argumentaram, ainda, que a seleção e a compensação podem ser favorecidas pelos dois modos de controle, primário e secundário. Assim, propuseram um modelo bidimensional de seleção/compensação e de controle primário/secundário que resulta em quatro tipos de estratégias de controle: primário seletivo, primário compensatório, secundário seletivo e secundário compensatório.

O controle primário seletivo refere-se ao investimento focalizado de recursos tais como esforço, tempo, capacidades e desenvolvimento de habilidades requeridas para o alcance de uma meta escolhida (p. ex. Aprender a tocar um instrumento musical). O controle primário compensatório diz respeito ao uso de recursos externos ao indivíduo - assistência de outras pessoas ou auxílios técnicos tais como próteses e órteses - requeridos quando as capacidades físicas ou cognitivas do indivíduo são insuficientes para atingir uma meta selecionada. O controle secundário seletivo refere-se às "representações internas" (Schulz \& Heckhausen, 1996, p. 710) relevantes do ponto de vista da motivação para a persecução de uma meta escolhida (p. ex. Valorizar a meta e/ou a própria capacidade para alcançá-la). O controle secundário compensatório diz respeito às estratégias que visam amortecer os efeitos negativos de perdas/falhas sobre a motivação do indivíduo para o controle primário (p. ex. Ajustamento do nível de aspiração, comparações estratégicas intra-individual e social).

Em seu esforço para mostrar que a função do controle secundário extrapola a compensação, Heckhausen e Schulz 
(1995) criticaram a literatura existente acerca do controle secundário, a qual teria enfatizado seu uso apenas no sentido de proteger o "bem-estar emocional e a auto-estima" (p. 286) do indivíduo em caso de falha no controle primário. Propuseram uma função adicional, a de manter o potencial do indivíduo para exercer o controle primário no futuro. Assim, em caso de perda ou ameaça ao controle primário, "as estratégias de controle secundário podem ajudar a minimizar perdas ou manter o controle primário, bem como expandir o potencial para o controle primário sem que o indivíduo tenha que se engajar fisicamente no ambiente" (p. 286).

Embora Heckhausen e Schulz (1995) não façam referência, vale ressaltar que esta função do controle secundário já havia sido vislumbrada por Rothbaum et al. (1982). Ao diferenciar o controle secundário do termo defesa, tal como utilizado na literatura da teoria da atribuição, a qual se refere ao esquecimento ou negação do fracasso como recurso para manter a auto-estima, Rothbaum et al. afirmaram: "nós consideraríamos a proteção da auto-estima por meio da negação como um esforço para manter a crença na eventual efetividade do controle primário - a capacidade para modificar o ambiente" (p. 9).

A novidade que Heckhausen e Schulz (1995) realmente introduziram, além da redefinição dos construtos de controle primário e secundário e da ênfase na primazia do primeiro sobre o segundo, é uma noção de controle secundário que adquire funções ligadas à seleção, a qual fica clara na definição da estratégia denominada de controle secundário seletivo. Além de ajudar a lidar com falhas/ perdas e de auxiliar na preservação do potencial do indivíduo para o controle primário, o controle secundário também "favorece diretamente o controle primário, dirigindo sua seletividade" (p. 286). Os autores argumentaram que, ao longo de seu desenvolvimento, os indivíduos devem fazer escolhas quanto às metas a perseguir, ou seja, realizar seleções; focalizar-se nas metas selecionadas a fim de atingi-las e, ao mesmo tempo, ignorar ou inibir alternativas não escolhidas. Assim, o controle secundário desempenharia "um papel essencial no sentido de capacitar o organismo para selecionar e focalizar-se em metas que expandem níveis existentes de controle primário" (p. 286). Isto, segundo os autores, seria conseguido de várias maneiras, tais como "elevar a atratividade de metas escolhidas, desengajar-se de alternativas de ação não escolhidas, ou superestimar competências pessoais" (p. 286).

O empenho de Heckhausen e Schulz (1995) no sentido de assegurar a função seletiva do controle secundário conduz a algumas reflexões. Em primeiro lugar, confere coerência interna à teoria, uma vez que reafirma a posição dos autores de ligar o controle primário estritamente à ação e o controle secundário, à cognição. Ressalte-se que as atribuições ao próprio esforço e capacidade foram concebidas por Rothbaum et al. (1982) como parte do empenho do indivíduo para obter controle primário. Uma vez que Rothbaum et al. conceberam controle primário e secundário como processos que envolvem tanto ação quanto cognição, sem colocar ênfase em um ou outro, provavel- mente incluiriam a tal função seletiva do controle secundário de Heckhausen e Schulz como função do controle primário, já que é dirigida à seleção e, como tal, faz parte do esforço do sujeito para modificar o ambiente.

Em segundo lugar, quando Heckhausen e Schulz (1995) se referem às estratégias de "ignorar ou inibir alternativas não escolhidas" ou de "desengajar-se de alternativas de ação não escolhidas" (p. 286) como controle secundário diretamente ligado à seletividade, ou seja, com função de elevar o comprometimento do indivíduo para com as metas selecionadas, os autores parecem não atentar para a forte carga auto-protetora, portanto compensatória, de tais estratégias. Tal imprecisão conduz à confusão conceitual.

Vale lembrar que Rothbaum et al. (1982) afirmaram que nenhum dos dois processos de controle existe em forma pura, que ambos estão freqüentemente inter-relacionados como, por exemplo, quando as pessoas negociam e entram em um acordo. Desta forma, o que parece ocorrer no caso dessa estratégia classificada por Heckhausen e Schulz (1995) como controle secundário seletivo é que o indivíduo lança mão dela concomitantemente a um processo de controle primário envolvido na escolha, como se fossem dois lados de uma mesma moeda.

O processo de decisão por uma entre várias opções é assaz complexo. O indivíduo avalia prós e contras de cada alternativa e, no momento em que escolhe uma delas, ganha e perde ao mesmo tempo. Assim, recorre a estratégias que lhe ajudem, por um lado, a lidar com as perdas inerentes às opções preteridas e, por outro, a engajar-se na alternativa selecionada. Este processo foi muito bem explicado por Festinger (1975) em sua célebre teoria da dissonância cognitiva. Entende-se, portanto, ser mais adequado classificar a estratégia desengajamento de alternativas de ação não escolhidas como controle secundário compensatório.

Heckhausen e Schulz (1995) consolidaram sua concepção da função seletiva do controle secundário quando afirmaram que "uma das principais funções do controle secundário é servir de apoio ao controle primário em termos de direcionamento meta-motivacional e metavolicional da ação" (p. 287), ou seja, dirigir o controle primário. Para argumentar a favor deste ponto, os autores agregaram sua noção de controle secundário ao Modelo Rubicão das fases da ação de H. Heckhausen ${ }^{1}$ (como citado em Heckhausen \& Schulz, 1995), o qual identifica a ação como um processo envolvendo quatro fases: motivação pré-decisão, volição pré-ação, volição da ação e motivação pós-ação.

De acordo com o Modelo Rubicão, a fase de motivação pré-decisão refere-se à avaliação dos prós e contras das várias alternativas de ação, antes da tomada de decisão. A fase de volição pré-ação diz respeito à espera do momento apropriado para executar a ação, cuja realização já consti-

\footnotetext{
${ }^{1} \mathrm{H}$. Heckhausen refere-se a outro autor com o mesmo sobrenome de Jutta Heckhausen, Heinz Heckhausen, autor do livro Motivação e ação (1991). New York: Springer.
} 
tuiria a fase de volição da ação. Finalmente, a fase de motivação pós-ação refere-se à avaliação do resultado da ação. As fases motivacionais seriam deliberativas - além da decisão pela ação, a avaliação da ação inclui atribuições causais e inferências para ações futuras. As fases volitivas, por sua vez, são consideradas de implementação.

Heckhausen e Schulz (1995) discutiram o valor adaptativo das estratégias de controle secundário em cada uma das fases da ação. Nas fases motivacionais - pré-decisão e pós-ação - o controle secundário seria utilizado como compensação. Nas fases volitivas - pré-ação e ação - essa estratégia seria empregada no sentido seletivo. Assim, na fase pré-decisória o controle secundário atuaria principalmente "em resposta a perdas antecipadas no controle primário” (p. 288). Já na fase pós-ação, operaria especialmente para ajudar o indivíduo a lidar com falhas no controle primário. De acordo com os autores, o primeiro caso corresponderia ao controle preditivo de Rothbaum et al. (1982), enquanto o segundo, ao interpretativo. Nas fases de pré-ação e ação, as estratégias de controle secundário auxiliariam o indivíduo "a iniciar uma seqüência de ações e a levá-la a cabo até que se complete" (p. 288), por exemplo, aumentar o valor da meta escolhida e/ou exagerar a probabilidade de sucesso no seu alcance (estratégias meta-motivacionais).

Heckhausen e Schulz (1995) deram ênfase especial às estratégias meta-motivacionais ressaltando que elas "incluem somente processos de auto-regulação dirigidos à realização da vontade. Desenvolver um plano de ação específico dirigido ao alcance de certa meta seria classificado como controle primário" (p. 288). Tal colocação reforça a tônica cognitiva que imprimem ao controle secundário, por um lado, e comportamental ao controle primário, por outro. Assim, conforme estes autores, as estratégias metamotivacionais seriam estratégias de controle secundário seletivo, uma vez que dirigem a ação, portanto, o controle primário. Considerando-se que estas estratégias fazem parte do esforço do sujeito para alcançar metas selecionadas, portanto para modificar o ambiente à sua vontade, provavelmente elas fariam parte do processo de controle primário na concepção de Rothbaum et al. (1982).

A teoria do controle no curso de vida tem sido testada em seus pressupostos, contudo, contribuições ou refinamentos aos conceitos propostos pelo modelo bidimensional de seleção/compensação e controle primário/secundário não foram encontrados. Há apoio empírico para as seguintes assertivas: (a) o controle primário se mantém ao longo da vida por meio de metas adequadas a idade (Heckhausen, 1997; Khoury, 2005; Peng, 1996; Wrosch, Heckhausen, \& Lachman, 2000); (b) o ajustamento dos processos de controle à estrutura de oportunidades, conforme os declínios relacionados à idade são mais adaptativos e estão relacionados à melhoria do bem-estar psicológico (Heckhausen, Wrosch, \& Fleeson, 2001; Wrosch \& Heckhausen, 1999); (c) o controle secundário (compensatório) prevalece em situações onde o controle primário é limitado, tais como doenças, favorecendo a adaptação (McQuillen, Licht, \& Licht, 2003; Thompson, Nanni, \& Levine, 1994). Há con- tradição com relação à proposição de que o controle secundário aumenta com a idade: uns a confirmam (Heckhausen, 1997; McConatha \& Huba, 1999; Peng, 1996) outros não (Chipperfield, Perry, \& Menec, 1999; Khoury, 2005). A seguir serão sumarizadas as contribuições aqui apresentadas.

\section{Considerações Finais}

Parece legítimo reconhecer que os processos de controle primário e secundário são fundamentais para a compreensão do desenvolvimento humano, da infância à velhice. Também parece lícito reconhecer a primazia do controle primário sobre o controle secundário. A capacidade de moldar o ambiente à sua vontade, de transformá-lo, adaptando-o às próprias necessidades e projetos é o que essencialmente distingue o homem dos outros animais.

Após toda a discussão aqui estabelecida e comungando da definição proposta por Rothbaum et al. (1982) entendese que controle primário e controle secundário são dois processos complexos, ambos envolvendo ação e cognição, os quais se distinguem em função do objetivo/finalidade do indivíduo: adaptar o ambiente a si ou adaptar-se ao ambiente. O controle primário diz respeito a esforços de realização, dirigidos à concretização de metas. $\mathrm{O}$ controle secundário se constitui em esforços de adaptação a situações percebidas como incontroláveis ou difíceis de controlar. A função do controle secundário é, portanto, compensatória. Por um lado, o controle secundário auxilia o indivíduo a lidar com perdas ou fracassos e, por outro, preserva a crença em sua capacidade (potencial) para exercer o controle primário, a despeito das adversidades.

Assim, no intuito de contribuir com as definições de Rothbaum et al. (1982), propõe-se conceituar controle primário como todos os esforços que um indivíduo empreende no sentido de modificar o ambiente - físico ou social - e adaptá-lo às suas necessidades, a fim de atingir suas metas. Controle secundário refere-se a todos os esforços que um indivíduo realiza para se adaptar ao ambiente e dançar conforme a música, especialmente a situações em que metas não foram alcançadas ou onde ocorreram perdas/falhas. Esses esforços podem ser em nível de ação/ comportamento ou de cognição/pensamento e podem ser empreendidos individualmente ou em grupo.

No que tange ao modelo bidimensional de seleção/compensação e de controle primário/secundário (Heckhausen \& Schulz, 1993, 1995; Schulz \& Heckhausen, 1996), bem como às quatro estratégias de controle derivadas a partir deste modelo, a discussão aqui travada conduz à seguinte conclusão. Excetuando-se o controle secundário compensatório, todas as outras estratégias de controle propostas por estes autores visam ao esforço de realização. Até mesmo a estratégia denominada de controle secundário seletivo. Como visto acima, sua função é aumentar o comprometimento do sujeito para com metas escolhidas e mantê-lo focalizado nestas metas a fim de atingi-las. Portanto, em última instância, essa estratégia visa ao controle primário. Uma vez que tal estratégia faz parte do empenho do sujeito para alcançar uma meta selecionada, seu con- 
teúdo seria mais adequadamente classificado como controle primário. Apoio empírico a estas considerações podem ser encontrados em Khoury (2005) e Nakajima e Muto (2007).

Se a estratégia denominada de controle secundário seletivo, pelas razões acima expostas, for considerada parte do controle primário restaria apenas um tipo de controle secundário, aquele cognominado de controle secundário compensatório. Todavia, a distinção do controle primário nas categorias seletivo e compensatório revela-se apropriada ao estudo do desenvolvimento humano, especialmente considerando-se que em todas as fases da vida, mormente na infância e na velhice, o ser humano necessita de ajuda externa para concretizar muitos de seus objetivos. Porém, estes termos exigem cautela em sua utilização, já que no controle primário dito compensatório o sujeito busca recursos que lhe auxiliem a levar a cabo sua seleção, ou seja, a atingir suas metas.

Espera-se que esta análise seja um primeiro passo no sentido de estimular a reflexão e expandir a discussão teórica que envolve os conceitos de controle primário e secundário.

\section{Referências}

Baltes, P. B., \& Baltes, M. M. (1990). Psychological perspectives on successful aging: The model of selective optimization with compensation. In P. B. Baltes, \& M. M. Baltes (Eds.), Successful aging: Perspectives from the behavioral sciences (pp. 1-34). New York: Cambridge University Press.

Band, E. B., \& Weisz, J. R. (1988). How to feel better when it feels bad: Children's perspectives on coping with everyday stress. Developmental Psychology, 24(2), 247-253.

Chipperfield, J. G., Perry, R. P., \& Menec, V. H. (1999). Primary and secondary control-enhancing strategies: Implications for health in later life. Journal of Aging and Health, 11(4), 517539.

Festinger, L. (1975). Teoria da dissonância cognitiva. Rio de Janeiro, RJ: Zahar.

Gould, S. J. (1999). A critique of Heckhausen \& Schulz's (1995) life-span theory of control from a cross-cultural perspective. Psychological Review, 106(3), 597-604.

Heckhausen, J. (1997). Developmental regulation across adulthood: Primary and secondary control of age-related challenges. Developmental Psychology, 33(1), 176-187.

Heckhausen, J. (2001). Adaptation and resilience in midlife. In M. E. Lachman (Ed.), Handbook of midlife development (pp. 345-394). New York: Wiley.

Heckhausen, J., \& Schulz, R. (1993). Optimization by selection and compensation: Balancing primary and secondary control in life-span development. International Journal of Behavioral Development, 16, 287-303.

Heckhausen, J., \& Schulz, R. (1995). A life-span theory of control. Psychological Review, 102, 284-304.

Heckhausen, J., \& Schulz, R. (1999). The primacy of primary control is a human universal: A reply to Gould's (1999) critique of the life-span theory of control. Psychological Review, 106(3), 605-609.

Heckhausen, J., Wrosch, C., \& Fleeson, W. (2001). Developmental regulation before and after a developmental deadline: The sample case of "biological clock" for childbearing. Psychology and Aging, 16(3), 400-413.
Khoury, H. T. T. (2005). Controle primário e controle secundário: Relação com indicadores de envelhecimento bem-sucedido. Tese de Doutorado não-publicada, Instituto de Psicologia, Universidade de Brasília, DF.

Krause, N. (2001). Social support. In R. H. Binstock \& L. K. George (Eds.), Handbook of aging and the social sciences (pp. 272-294). San Diego, CA: Academic Press.

Lefcourt, H. M. (1976). Locus of control: Current trends in theory and research. Hillsdale, NJ: Erlbaum.

McConatha, J. T., \& Huba, H. M. (1999). Primary, secondary, and emotional control across adulthood. Current Psychology: Developmental, Learning, Personality, Social, 18(2), 164-170.

McQuillen, A. D, Licht, M. H., \& Licht, B. G. (2003). Contributions of disease severity and perceptions of primary and secondary control to the prediction of psychosocial adjustment to Parkinson's disease. Health Psychology, 22(5), 504-512.

Nakajima, Y., \& Muto, T. (2007). Job-hunting by female university students as a goal-action-outcome process: Impact of vocational motives and control strategies. Japanese Journal of Educational Psychology, 55(3), 403-413.

Peng, Y. (1996). Primary and secondary control: Cross-cultural and life-span developmental perspectives. Paper presented at the $13^{\text {th }}$ Biennial Meeting of Institutional Society for the Study of Behavioural Development, Amsterdan, Netherlands.

Rothbaum, F., Weisz, J. R., \& Snyder, S. S. (1982). Changing the world and changing the self: A two-process model of perceived control. Journal of Personality and Social Psychology, 42, 5-37.

Rotter, J. B. (1966). Generalized expectancies for internal versus external control of reinforcement. Psychological Monographs, $80,1-28$.

Schulz, R., \& Heckhausen, J. (1996). A life-span model of successful aging. American Psychologist, 51, 702-714.

Seligman, M. E. P. (1977). Desamparo: Sobre depressão, desenvolvimento e morte. São Paulo, SP: Hucitec.

Thompson, S. C., Nanni, C., \& Levine, A. (1994). Primary versus secondary and central versus consequence-related control in HIV-positive men. Journal of Personality and Social Psychology, 67(3), 540-547.

Thurber, C. A., \& Weisz, J. R. (1997). "You can try or you can just give up": The impact of perceived control and coping style on childhood homesickness. Developmental Psychology, 33(3), 508-517.

Weisz, J. R., McCabe, M. A., \& Dennig, M. D. (1994). Primary and secondary control among children undergoing medical procedures: Adjustment as a function of coping style. Journal of Consulting and Clinical Psychology, 62(2), 324-332.

Weisz, J. R., Rothbaum, F. M., \& Blackburn, T. C. (1984). Standing out and standing in: The psychology of control in America and Japan. American Psychologist, 39(9), 955-969.

Wrosch, C., \& Heckhausen, J. (1999). Control processes before and after passing a developmental deadline: Activation and deactivation of intimate relationship goals. Journal of Personality and Social Psychology, 77(2), 415-427.

Wrosch, C., Heckhausen, J., \& Lachman, M. E. (2000). Primary and secondary control strategies for managing health and financial stress across adulthood. Psychology and Aging, 15(3), 387-399. 